www.jmscr.igmpublication.org

Impact Factor (SJIF): 6.379

Index Copernicus Value: 79.54

ISSN (e)-2347-176x ISSN (p) 2455-0450

crossrefDOI: https://dx.doi.org/10.18535/jmscr/v6i9.125

Journal Of Medical Science And Clinical Research

IGM Publication

An Official Publication of IGM Publication

\title{
A Prospective Study to Evaluate Cardiac Functional Status in Permanent Pacemaker Implanted Patients at a Tertiary Care Centre
}

\author{
Authors \\ Prateek Chaudhury ${ }^{1}$, Lipika Adhikari ${ }^{*}$, Biswajit Majumdar ${ }^{3}$, Abhay Chaturbedi ${ }^{4}$ \\ ${ }^{1,4}$ DM Senior Resident, Cardiology Department, RG Kar Medical College, Kolkata \\ ${ }^{2}$ Assistant Professor, Cardiology Department, RG Kar Medical College, Kolkata \\ ${ }^{3}$ Associate Professor, Cardiology Department, RG Kar Medical College, Kolkata \\ *Corresponding Author \\ Lipika Adhikari \\ Assistant Professor, Cardiology Department, RG Kar Medical College, Kolkata \\ Address: C/O Manoj Adhikari, School Danga, post \& district Bankura, West Bengal, PIN 722101, India
}

\begin{abstract}
Our study aimed at finding the incidence of overt heart failure or asymptomatic left ventricular systolic/diastolic dysfunction and cardiac dyssynchrony in patients undergoing single or dual chamber cardiac pacing and its impact on exercise capacity. 80 patients undergoing permanent pacemaker implantation (single or double chamber) were examined for various predetermined echocardiographic parameters of left ventricular systolic function, diastolic function and dyssynchrony before and one year after implantation. Also the impact of pacing on the exercise capacity is assessed by six minute walk test. The various echocardiographic parameters of left ventricular systolic function, diastolic function and dyssynchrony namely, Ejection Fraction (EF), E' velocity, Interventricular Mechanical Delay (IVMD), Septum to Posterior Wall Motion Delay (SPWMD), Time to peak Systolic velocity between the septal and lateral wall $(T s-S L)$, showed no significant variation between before and after pacemaker implantation values. In patients with normal ejection fraction and with no structural heart disease there was no significant difference in the systolic, diastolic function and various dyssynchrony indices after one year of right ventricular pacing.Also right ventricular pacing did not affect the functional capacity of the patient as assessed by six minute walk test.
\end{abstract}

Keywords: Cardiac pacing, Echodoppler parameters, Left ventricular systolic function, Left ventricular diastolic function, Six minute walk test.

\section{Introduction}

Cardiac pacing at any point of the ventricle alters the natural heart activation and contraction pattern, as the stimulus conduction velocity is slower across the ventricular myocardium when compared with that resulting from the specialized His-Purkinje system ${ }^{[1,2]}$. RV apical pacing can induce both interventricular dyssynchrony [between the RV and the LV] and intraventricular dyssynchrony (within the LV) ${ }^{[3]}$.

It has been demonstrated that the presence of ventricular dyssynchrony is associated with an increased risk of cardiac morbidity ${ }^{[4]}$ and mortality ${ }^{[5]}$ in heart failure patients. In addition, it 
has been suggested that the presence of mechanical dyssynchrony after long-term RV apical pacing is associated with reduced LV systolic function and deterioration in the functional capacity ${ }^{[3]}$.

Left ventricular diastolic function is an equally important component of the cardiac cycle, which is closely coupled with systolic function. In particular, early diastolic function is an energydependent process consuming ATP, and yet is also dependent on the mechanical properties of the ventricle such as chamber pressure, annulus recoil, and stiffness ${ }^{[6]}$. However, there is little information on the effects of RVA pacing on diastolic function. Early studies were unable to draw a clear conclusion on the effect of RVA pacing on LV diastolic function, and its relationship with changes in systolic function ${ }^{[7-10]}$. In the background of this knowledge we seek to find the prevalence of new onset LV systolic dysfunction and cardiac dyssynchrony and its impact on the functional status in patients undergoing single or dual chamber PPM implantation

\section{Materials and Methods}

A total of 80 patients undergoing single/dual pacemaker implantation at R. G. Kar Medical College over a span of 1 year from JAN 2016 to JAN 2017 formed the study population.

\section{Inclusion Criteria}

1. All patients undergoing PPI for Atrioventricular node or Sinus node dysfunction.

2. No structural heart disease at the time of implantation.

3. Ability to provide written consent.

\section{Exclusion Criteria}

1. Comorbidities that themselves might cause LV remodelling
a. History of chemotherapy with cardiotoxic agents,
b. Hypertensive heart disease,
c. Chronic alcohol abuse, and
d. Valvular heart disease

2. Chronic disesases like CKD, CLD, malignancies etc.

3. H/o ACS in past or during study period

\section{Study Protocol}

All patients underwent echocardiography, ECG and detailed clinical examination before and after 1 year of endovenous single/dual chamber pacing. 6 minute walk test (6MWT) was also performed before or within 1 month and after 1 year of endovenous single/dual chamber pacing (if there is no physical disability or other contraindications to 6MWT).

\section{Before Pacemaker Implantation Echocardiography}

Transthoracic echocardiography examination was done using Philips EPIQ7C machine to define cardiac anatomy, ventricular function, and valvular competence. LV posterior and septal wall thickness and LV end-diastolic and end-systolic diameters were obtained by averaging the measurements over 3 consecutive cardiac cycles with M-mode echocardiography.

Left ventricular ejection fraction was assessed using Simpson's method as a measure of ventricular systolic function. Pulse-wave TDI was performed in the apical four-chamber view by placing a $5 \mathrm{~mm}$ sample volume at the septal and lateral mitral annulus to assess the early diastolic $\left(E^{\prime}\right)$ velocities acquired from the mean value of three cardiac cycles. The right ventricular mechanical delay (RVMD) and left ventricular mechanical delay (LVMD) - i.e. the intervals between the beginning of the QRS complex and the opening of the semilunar valves-was determined by PW-Doppler. Interventricular dyssynchrony is defined as an interventricular mechanical delay (IVMD) > 40 ms.Septal-toposterior wall-motion delay (SPWMD) measured by M-mode color-TDI is technically the simplest approach to quantify LVMD. The addition of color TDI to M-mode aids in identifying the transition from inward to outward motion in the septum and posterior wall. Normally SPWMD is less than $40 \mathrm{~ms}$. The cut-off value of greater than or equal to $130 \mathrm{~ms}$ is a marker of $\mathrm{LV}$ 


\section{JMSCR Vol||06||Issue||09||Page 715-721||September}

dyssynchrony in patients with non-ischemic cardiomyopathy. Time-to-peak velocity between the septal and lateral wall was measured using the 4-chamber color TDI images from the beginning of the QRS complex, and the maximal time-topeak difference between the basal segments of the septal and the lateral walls was calculated (TsSL). A predefined cut off $\geq 65$ was considered dyssynchrony.

\section{Electrocardiography}

Baseline ECG was done during index admission before and after PPI and then at 2 months, 6 months and 1 year after implantation to detect new, delayed and late onset rhythm abnormalities.

6 Minute Walk Test:

6 minute walk test was done before or within 1 month of PPI.

\section{After Pacemaker Implantation}

ECHO, ECG and 6 min walk test will be repeated after 1 year ofPPI for reassessment of the above mentioned parameters.

\section{Statistical Analysis}

The collected data were tabulated and statistically analyzed using the SPSS version 20.0 for Windows (SPSS Inc., Chicago, Illinois, USA). Comparisons between the baseline and at one year parameters were performed using the Wilcoxon
Signed Ranks Test. A probability value of 0.05 was considered to be statistically significant

\section{Results and Observations}

In the study population, 52(65\%) were male and $28(35 \%)$ were female subjects. Mean age of the study population was $66.57 \pm 7.031$ years. Out of the total 80 patients undergoing permanent pacemaker implantation, 48(60\%) were hypertensive and 21(26.2\%) patients were diabetic.

In the patients undergoing permanent pacemaker implantation 49(61.3\%) had complete heart block, $21(26.3 \%)$ had sick sinus syndrome, $8(10 \%)$ had trifasicular block and $2(2.5 \%)$ had bifasicular block, with all patients having class 1 indication for permanent pacing.

Out of the total 80 patients, 61 patients $(76.3 \%)$ underwent single chamber permanent pacemaker implantation and the rest 19(23.8\%) underwent dual chamber permanent pacemaker implantation. There were various variables, namely Ejection Fraction (EF), $\mathrm{E}^{\prime}$ velocity, Interventricular Mechanical Delay (IVMD), Septum to Posterior Wall Motion Delay (SPWMD), Time to peak Systolic velocity between the septal and lateral wall(Ts-SL) and 6 Minute Walk Test, which were examined at baseline and at one year to assess the impact of right ventricular pacing(Table 1).

Table 1: Various variables studied at baseline and at one year in the study

\begin{tabular}{|c|c|c|c|c|c|}
\hline & & MEAN & $\mathbf{N}$ & STD. DEVIATION & STD. ERROR MEAN \\
\hline \multirow[t]{2}{*}{ Pair 1} & $\mathbf{E F}$ & 62.2963 & 80 & 2.39363 & .26762 \\
\hline & EF AT ONE YEAR & 62.0487 & 80 & 2.26425 & .25315 \\
\hline \multirow[t]{2}{*}{ Pair 2} & $\mathbf{E}^{\prime}$ & 9.9712 & 80 & 1.72224 & .19255 \\
\hline & E' AT ONE YEAR & 9.9263 & 80 & 1.80952 & .20231 \\
\hline \multirow[t]{2}{*}{ Pair 3} & IVMD & 24.6500 & 80 & 8.15219 & .91144 \\
\hline & IVMD AT ONE YEAR & 24.9250 & 80 & 8.45206 & .94497 \\
\hline \multirow[t]{2}{*}{ Pair 4} & SPWMD & 35.1750 & 80 & 6.18855 & 69190 \\
\hline & SPMWD AT ONE YEAR & 35.4250 & 80 & 6.11447 & .68362 \\
\hline \multirow[t]{2}{*}{ Pair 5} & Ts - SL & 42.3000 & 80 & 7.50595 & .83919 \\
\hline & Ts - SL AT ONE YEAR & 42.5875 & 80 & 7.80570 & .87270 \\
\hline \multirow[t]{2}{*}{ Pair 6} & 6 MWT & 439.8750 & 80 & 86.26840 & 9.64510 \\
\hline & 6 MWT AT ONE YEAR & 439.8125 & 80 & 92.35568 & 10.32568 \\
\hline
\end{tabular}

All the variables examined in the study showed non-significant difference between baseline and one year values (Table 2). 
Table 2 Showing variation of different parameters studied in pacemaker implanted patients at baseline and at one year (Wilcoxon Signed Ranks Test)

\begin{tabular}{|l|l|c|c|c|c|}
\hline \multicolumn{2}{|l|}{} & MEAN & $\begin{array}{c}\text { STD. } \\
\text { DEVIATION }\end{array}$ & $\begin{array}{c}\text { STD. ERROR } \\
\text { MEAN }\end{array}$ & $\begin{array}{c}\text { SIG. (2- } \\
\text { TAILED) }\end{array}$ \\
\hline Pair 1 & EF - EF AT ONE YEAR & .24750 & 1.47029 & .16438 & .092 \\
\hline Pair 2 & $\mathbf{E}^{\prime}$ - E' AT ONE YEAR & .04500 & .61990 & .06931 & .751 \\
\hline Pair 3 & IVMD - IVMD AT ONE YEAR & -.27500 & 1.90253 & .21271 & .086 \\
\hline Pair 4 & SPWMD- SPMWD AT ONE YEAR & -.25000 & 2.10785 & .23566 & .150 \\
\hline Pair 5 & Ts - SL - Ts - SL AT ONE YEAR & -.28750 & 1.57668 & .17628 & .083 \\
\hline Pair 6 & 6 MWT - 6 MWT AT ONE YEAR & .06250 & 18.31880 & 2.04810 & .713 \\
\hline
\end{tabular}

\section{Discussion}

Long-term effects of RV apical pacing have been studied, and not much information is available on the acute and early effects of RV pacing on LV function and LV dyssynchrony ${ }^{[11]}$. Our study aimed to demonstrate the early impact of RV apical pacing induced by single chamber and dualchamber pacemakers on LV systolic and diastolic functions in patients with preserved $\mathrm{EF}$

\section{Effect on left ventricular systolic functions}

In our study, there was no statistically significant difference within repeated measurements of the LV EF over time ( $p=0.136)$. Mohan et al. ${ }^{[12]}$ in their study found no significant difference in the resting LV EF in the long-term follow-up of AAIpaced and VVI-paced patients of sinus node dysfunction without structural heart disease. Similarly, Anderson et al. ${ }^{[13]}$ in their study of sick sinus syndrome patients, found no difference in the incidence of clinical congestive heart failure or LV dimensions between AAI and VVI pacing modes on long-term follow-up. In contrast, Pehrsson et al. ${ }^{[14]}$ found an increase in the enddiastolic volume in VVI-paced patients after 3 months. Likewise, Faerestrand et al. ${ }^{[15]}$ found greater resting $\mathrm{LV}$ volumes and lesser $\mathrm{EF}$ in patients paced on VVI rather than with the physiological pacing mode. Dwivedi et al. ${ }^{[16]}$ studied 48 patient with VVI pacing and found that the LV EF decreased progressively from baseline $(61.82 \pm 10.36 \%)$ and was statistically significant at 6 months $(52.52 \pm 12.11 \%, P<0.05)$. The cardiac dimensions, the LV end diastolic dimension and the LV end-systolic dimension increased significantly over their corresponding baseline values by 6 months $(P<0.05)$. However, the aforementioned study used a higher percentage of pacing $(>90 \%)$ in all patients, and this may be the cause of early effects on the LV dimension and systolic functions.

\section{The effect on left ventricular diastolic functions}

We did not find any statistically significant difference between both groups regarding septal and lateral $\mathrm{E}^{\prime}$ waves by pulsed-tissue Doppler. This was the same as in previous studies; they also found no significant changes in the diastolic function. Brandon K. Fornwalt ${ }^{[17]}$ et al. acute RVA pacing does not affect diastolic synchrony (Diastolic dyssynchrony was $11 \pm 13 \mathrm{~ms}, 15 \pm 18$ ms and $15 \pm 27 \mathrm{~ms}$ for sinus rhythm, atrial pacing and right ventricular pacing respectively " $p$ " = 0.375). Naegeli et al. ${ }^{[18]}$ conducted a single-blind, randomized crossover study evaluating the impact of the $\mathrm{DDD}(\mathrm{R})$ mode as against the $\mathrm{VVI}(\mathrm{R})$ mode on objective and functional parameters. They found no significant changes in the transmitral flow propagation rate and the $\mathrm{E} / \mathrm{E}^{\prime}$ ratio. Kojuri et al. $^{[19]}$ also found no significant changes in $\mathrm{E}$ and A'by pulsed-tissue Doppler between DDD and VVI.

There are few studies that conflict with our results. Betocchi et al. ${ }^{[10]}$ found that acute ventricular pacing increases diastolic dyssynchrony relative to atrial pacing in patients with coronary artery disease. However, in patients with coronary disease, early onset of lengthening may occur in hypoxic muscle supplied by partially occluded coronary arteries ${ }^{[20,21]}$. In addition, 
hypoxia suppresses the load dependence of relaxation $^{[22]}$ suggesting that patients with coronary artery disease may have a different response to acute pacing relative to the healthy patients in our study.

\section{Interventricular mechanical dyssynchrony}

In our study there was no significant difference within the repeated measurement of IVMD at baseline $(24.650 \pm 8.152 \mathrm{~ms})$ and at one year $(24.925 \pm 8.452)$, supported by a " $p$ " value of .086. Similarly Tops et al. ${ }^{[3]}$ showed that even after long-term RV pacing, mean interventricular delay did not increase significantly in the patients without LV dyssynchrony ( $24 \pm 14$ ms vs. $35 \pm 25$ $\mathrm{ms}$, "p" > .05). In contrast, in the same study interventricular delay revealed a significant increase in the patients with LV dyssynchrony after long-term RV pacing $(25 \pm 12$ ms vs. $49 \pm$ $19 \mathrm{~ms}$, "p" $=0.05$ ).

\section{Intraventricular dyssynchrony}

Both M-mode using SPWMD and TDI using the septal-to-lateral delay have proven to be effective in the detection of LV dyssynchrony ${ }^{[23,24]}$. In our study, change in SPWMD and Ts-SL from baseline to one year was not significant (" $p$ " = .150 and .083 repectively).

Previous studies have shown that ventricular dyssynchrony may be present in up to $50 \%$ of the patients after long-term RV apical pacing ${ }^{[25-27]}$, which is in contrast to our findings. This can be partially explained by the shorter follow up period in our study ( 1 year) which was more (3 to 5 years) in the studies where ventricular dyssynchrony was seen associated with right ventricular pacing. In the study by Schmidt $M$ et al. $^{[25]}$ where significant LV dyssynchrony developed after right ventricular pacing, had patients with severely depressed left ventricular ejection fraction, whereas in our study no patient had any structural heart disease. This can again explain the discrepancy of results between the two studies. .

It remains, however, undetermined why some patients develop LV dyssynchrony during RV pacing while other patients do not.

\section{Functional assessment}

In accordance with the other parameters of systolic and diastolic function, the functional capacity of the subjects as assessed by six minute walk test also did not show any statistically significant ("p" = .713) difference between baseline $(439.875 \pm 86.268 \mathrm{~m})$ and at one year $(439.812 \pm 92.356 \mathrm{~m})$ measurements.

\section{Limitations}

The present analysis focuses on the short-term impact of RV apical pacing on LV functions and LV dyssynchrony and does not provide information about the long-term consequences. Also the number of patients was relatively small in this study. There was no control population to assess normal variation of various parameters with age. Electrocardiographic parameters like QRS duration and percent of paced beats was not determined and the site of RV pacing was not taken into account. Comparative analysis between patients undergoing single and double chamber pacemaker cannot be done because of difference in the baseline characters of the two groups. Finally better techniques, like 3D speckle tracking may have assessed intraventricular dyssynchrony better than the techniques used in the current study.

\section{Conclusion}

Right ventricular apical pacing is an integral part of the treatment of brady-arrhythmias for the majority of patients receiving pacemakers. Right ventricular apical pacing is, however, an often pathologic substitute for intrinsic ventricular activation over the His-Purkinje system. Several reports indicate that this form of pacing is detrimental potentially increasing the risk of heart failure episodes and death, particularly in patients with abnormal LV function.

In our study, done on patients with normal ejection fraction and with no structural heart disease however has not shown any significant difference in the systolic and diastolic function after one year of right ventricular pacing. 
Various parameters of inter and intra ventricular dyssynchrony also showed non-significant variation between baseline.

Also right ventricular pacing did not affect the functional capacity of the patient as assessed by six minute walk test in our study.

Although much has been said regarding the detrimental effects of right ventricular pacing, in patients with good left ventricular function it is still a good and cost effective treatment for bradyarrythmias.

\section{References}

1. Prinzen $\mathrm{FW}$, Augustijn $\mathrm{CH}$, Arts $\mathrm{T}$, Allessie MA, Reneman RS. Redistribution of myocardial fiber strain and blood flow by asynchronous activation. Am J Physiol 1990; 259:H300-H308.

2. Manolis AS. The deleterious consequences of right ventricular apical pacing: time to seek alternate site pacing. Pacing ClinElectrophysiol 2006;29:298-315.

3. Tops LF, Schalij MJ, Holman ER, van Erven L, van der Wall EE, Bax JJ. Right ventricular pacing can induce ventricular dyssynchrony in patients with atrial fibrillation after atrioventricular node ablation. J Am CollCardiol 2006;48:16428.

4. Bader H, Garrigue S, Lafitte S, Reuter S, Reuter S, Jaïs P, et al. Intra-left ventricular electromechanical asynchrony. A new independent predictor of severe cardiac events in heart failure patients. J Am Coll Cardiol 2004;43:248-56.

5. Cho GY, Song JK, Park WJ, Han SW, Choi SH, Doo YC, et al. Mechanical dyssynchrony assessed by tissue Doppler imaging is a powerful predictor of mortality in congestive heart failure with normal QRS duration. J Am Coll Cardiol 2005; 46:2237-2243.

6. Gibson DG, Francis DP. Clinical assessment of left ventricular diastolic function. Heart 2003;89:231-8.
7. Litwin SE, Gorman G, Huang SK. Effects of different pacing modes on left ventricular relaxation in closed-chest dogs. Pacing ClinElectrophysiol 1989;12: 1070 -6 .

8. Zile MR, Blaustein AS, Shimizu G, Gaasch WH. Right ventricular pacing reduces the rate of left ventricular relaxation and filling. J Am CollCardiol 1987;10: 702 -9.

9. Bedotto JB, Grayburn PA, Black WH, Raya TE, McBride W, Hsia HH, Eichhorn EJ. Alterations in left ventricular relaxation during atrioventricular pacing in humans. J Am CollCardiol 1990;15:658 64.

10. Betocchi S, Piscione F, Villari B, Pace L, Ciarmiello A, Perrone-Filardi P, Salvatore C, Salvatore M, Chiariello M. Effects of induced asynchrony on left ventricular diastolic function in patients with coronary artery disease. J Am CollCardiol 1993;21:1124 -31.

11. Fornwalt BK, Cummings RM, Arita T, Delfino JG, Fyfe DA, Campbell RM, et al. Acute pacing-induced dyssynchronous activation of the left ventricle creates systolic dyssynchrony with preserved diastolic synchrony. J Cardiovasc Electrophysiol 2008; 19:483-8

12. Mohan JC, Sethi KK, Arora R, Khalilullah M. Comparative evaluation of left ventricular function in sick sinus syndrome on different long-term pacing modes. Indian Heart J 1994; 46:303-6.

13. Andersen HR, Thuesen L, Bagger JP, Vesterlund T, Thomsen PE. Prospective randomised trial of atrial versus ventricular pacing in sicksinus syndrome. Lancet 1994; 344:1523-8.

14. Pehrsson SK, Aström H, Bone D. Left ventricular volumes with ventricular inhibited and atrial triggered ventricular pacing. Acta Med Scand 1983; 214:305310. 
15. Faerestrand S, Ohm OJ. A time related study by Doppler and $M$ mode echocardiography of haemodynamics, heart size and AV valvular functions during activity sensing rate responsive ventricular pacing. Pacing Clin Electrophysiol 1987; 10:507-18.

16. Dwivedi SK, Bansal S, Puri A, Makharia MK, Narain VS, Saran RK, et al. Diastolic and systolic right ventricular dysfunction precedes left ventricular dysfunction in patients

17. Brandon K. Fornwalt, B.S., Rose M. Cummings et al. Acute Pacing-Induced Dyssynchronous Activation of the Left Ventricle Creates Systolic Dyssynchrony with Preserved Diastolic Synchrony. J CardiovascElectrophysiol. 2008 May ; 19(5): 483-488.

18. Naegeli B, Kurz DJ, Koller D, Straumann E, Furrer M, Maurer D, et al. Single chamber ventricular pacing increases markers of left ventricular dysfunction compared with dual-chamber pacing. Europace 2007; 9:194-9.

19. J Kojuri, E Atabati, S Moslemi. Assessment of BNP level in patients with single chamber and dual chamber pacemakers. IntCardiovasc Res J 2010; 4:118-22.

20. Theroux P, Ross J Jr, Franklin D, Kemper WS, Sasyama S. Regional myocardial function in the conscious dog during acute coronary occlusion and responses to morphine, propranolol, nitroglycerin, and lidocaine. Circulation. 1976; 53:302-14.

21. Wiegner AW, Allen GJ, Bing OH. Weak and strong myocardium in series: Implications for segmental dysfunction. Am J Physiol. 1978; 235:H776-H783.

22. Brutsaert DL, Housmans PR, Goethals MA. Dual control of relaxation. Its role in the ventricular function in the mammalian heart. Circ Res. 1980; 47:637-52.
23. Pitzalis MV, Iacoviello M, Romito R, et al. Cardiac resynchronization therapy tailored by echocardiographic evaluation of ventricular asynchrony. J Am CollCardiol 2002;40:1615-22.

24. Bax JJ, Bleeker GB, Marwick TH, et al. Left ventricular dyssynchrony predicts response and prognosis after cardiac resynchronization therapy. J Am CollCardiol 2004;44:1834 - 40.

25. Schmidt M, Bromsen J, Herholz C, et al. Evidence of left ventricular dyssynchrony resulting from right ventricular pacing in patients with severely depressed left ventricular ejection fraction. Europace 2007; 9: 34-40.

26. Thambo JB, Bordachar P, Garrigue S, et al. Detrimental ventricular remodeling in patients with congenital complete heart block and chronic right ventricular apical pacing. Circulation 2004; 110: 3766 -72.

27. Tops LF, Suffoletto MS, Bleeker GB, et al. Speckle-tracking radial strain reveals left ventricular dyssynchrony in patients with permanent right ventricular pacing. J Am CollCardiol 2007;50:1180-8. 